OPEN ACCESS

Edited by:

James Lloyd,

Stellenbosch University, South Africa

Reviewed by:

Ana López Sánchez,

Unviersity of Sheffield, UK

Florencia Pia Olivieri,

Universidad Nacional de Mar del

Plata, Argentina

*Correspondence:

Magdalena Arasimowicz-Jelonek marasimowicz@wp.pl

Specialty section:

This article was submitted to

Plant Biotechnology,

a section of the journal

Frontiers in Plant Science

Received: 02 May 2015

Accepted: 25 September 2015

Published: 15 October 2015

Citation:

Floryszak-Wieczorek J,

Arasimowicz-Jelonek M

and Abramowski D (2015)

$B A B A$-primed defense responses to Phytophthora infestans in the next vegetative progeny of potato.

Front. Plant Sci. 6:844.

doi: 10.3389/fpls.2015.00844

\section{BABA-primed defense responses to Phytophthora infestans in the next vegetative progeny of potato}

\author{
Jolanta Floryszak-Wieczorek ${ }^{1}$, Magdalena Arasimowicz-Jelonek ${ }^{2 *}$ and \\ Dariusz Abramowski ${ }^{1}$
}

${ }^{1}$ Department of Plant Physiology, Poznan University of Life Sciences, Poznan, Poland, ${ }^{2}$ Department of Plant Ecophysiology, Faculty of Biology, Adam Mickiewicz University, Poznan, Poland

The transcript of the PR1 gene accumulation as an informative marker of systemic acquired resistance (SAR) was analyzed in $\beta$-aminobutyric acid (BABA) primed potato in the short-lasting ( 3 days) and long-lasting (28 days) time periods after induction and in the vegetative descendants of primed plants derived from tubers and from in vitro seedlings. BABA pretreatment resulted either in minimal or no PR1 gene expression, but sequential treatment with BABA followed by virulent Phytophthora infestans provided data on the imprint of post-stress information and its duration until fertilization, in the form of an enhanced PR1 transcript accumulation and a transient increase of basal resistance to the late blight disease. The primed state for defense of the susceptible potato cultivar was transmitted to its vegetative progeny as a potentiated PR1 mRNA accumulation following challenge inoculation. However, variation was observed between vegetative accessions of the BABA-primed potato genotype in responsiveness to disease. In contrast to plants derived from tubers, potato propagated through in vitro seedlings largely lost inducible resistance traits, although itretained primed PR1 gene expression.

Keywords: next-generation SAR, PR1, Phytophthora infestans, late blight, potato defense, priming of defense

\section{INTRODUCTION}

In order to develop novel strategies for biotechnological improvement of plant immunity it is necessary to enhance plant recognition capacities for potential attackers, thus boosting the executive responses of disease resistance in plants. Many valuable genotypes of crop plants possess low basal immunity, generally too weak to effectively prevent disease. However, susceptible plants can alter innate immunity through stimulation of systemic defense responses. Plants trigger systemic acquired resistance (SAR) as a result of a frequently weak and local primary infection, caused by various pathogenic and non-pathogenic microorganisms, which is manifested in an enhanced potential to mount immune responses to subsequent infections (Oostendorp et al., 2001; Prime-A-Plant Group, 2006). Factors boosting crop innate immunity include various synthetic compounds known as SAR inducers (Conrath, 2011). This chemical-based technology with a rich arsenal of new synthetic elicitors may be successfully applied in longlasting crop protection against biotic stresses (Bektas and Eulgem, 2015). Because SAR inducers can offer disease limitation, without the need to be directly toxic for plant or pathogenic microorganisms, they might be promising, environmentally friendly alternatives to conventional pesticides. 
Physiological pre-conditioning for faster and stronger plant protection following challenged inoculation may be realized in the strategy of direct induced responses or be based on the phenomenon of priming (Conrath, 2011; Pastor et al., 2013). In contrast to directly induced hyperergic defense responses, priming preliminarily generates changes in the normoergic defense synchronized with the potential storage of information on previous sensing (Janus et al., 2013). The stress imprint is generally composed of biochemical and epigenetic changes (Bruce et al., 2007). The above-mentioned metabolic adaptations to new environmental conditions do not pertain to changes in DNA sequences, but consist of a modification, reversible by different enzymes of DNA- and histone-related proteins, which affects control of gene transcription activities (Zhang, 2008; van den Burg and Takken, 2009; Fu and Dong, 2013).

An important breakthrough in our knowledge on the longterm post-stress metabolic memory in plants was made in 2012, when three independent research groups, i.e., Luna et al. (2012), Pieterse (2012), Rasmann et al. (2012), and Slaughter et al. (2012), revealed evidence for intergeneration inheritance of SAR in plants in relation to biotic factors. Inducing plant defense is a very complex phenomenon because the final result depends on the effectiveness of the SAR inductor, defense responsiveness of the plant and environmental conditions.

It is generally accepted that $\beta$-aminobutyric acid (BABA), a non-protein amino acid, is a potent priming agent of SAR in plants. A high effectiveness of the BABA inducer in enhancing resistance was documented in many other pathogen-plant systems, including also the potato-Phytophthora infestans system (Cohen, 2002; Baider and Cohen, 2003; Si-Ammour et al., 2003; Ton and Mauch-Mani, 2004; Hamiduzzaman et al., 2005; Ton et al., 2005; Andreu et al., 2006; Dubreuil-Maurizi et al., 2010; Worrall et al., 2012; Janus et al., 2013).

Potato (Solanum tuberosum L.) is the fourth most frequently grown crop plant in the world and after wheat and rice it is the third crop in order of importance for human consumption (Haverkort et al., 2009). In turn, potato late blight caused by an oomycete, $P$. infestans (Mont.) de Bary, is one of the most devastating plant diseases worldwide. Losses caused by $P$. infestans are estimated at approximately $16 \%$ of annual world potato production ( $€ 5.2$ billion per annum) and costs of protection against late blight are estimated at millions of dollars as well. Nowadays, late blight control is based on the use of fungicides, which apart from causing economical losses have a negative impact on the environment. Cultivars Russet Burbank from the USA and Bintje from the Netherlands, both more than 100 years old, are still grown widely because of their superior quality and because growers use chemicals to control late blight (Haverkort et al., 2009). In view of this fact new strategies for biotechnological improvement of plant immunity involving the SAR inducers could provide novel agrochemicals to protect crops from diseases.

In our previous papers it was revealed that among various tested SAR inducers only BABA turned out to be an effective factor stimulating callose apposition and promoting systemic resistance to the pathogen in a potato cultivar ('Bintje') susceptible to P. infestans (Floryszak-Wieczorek et al., 2012; Janus et al., 2013).

In turn, in the presented study we focused on BABAprimed systemic resistance in the same and the next vegetative progeny of a potato cultivar susceptible to $P$. infestans. We found that the primed potato in the short-lasting (3 days) and long-lasting (28 days) time periods after induction and in its vegetative descendants of primed plants derived from tubers after challenged inoculation with the oomycete pathogen exhibited afaster and stronger PR1 transcript accumulation and limitation of late blight disease progress.

\section{MATERIALS AND METHODS}

\section{Experimental Design for the Generation of Progeny Lines}

Plants were treated with different BABA concentrations as indicated below. Immunization was performed by spraying potato leaves with a selected dose of BABA ( $3 \mathrm{ml}$ per plant) at the stage of 7-8 leaves of parental plants $\left(\mathrm{B}_{0}\right)$. Some BABAsensitized plants were inoculated with a $P$. infestans zoospore suspension in order to estimate their immunization level and disease progress. A separate batch of plants was grown until the phase of flowering $\left(\mathrm{B}_{0} / \mathrm{B}_{1}\right.$; ca. 28 days $)$ and then it was subjected to disease pressure. $A$ fraction of $\mathrm{B}_{0} / \mathrm{B}_{1}$ plants was used as the initial material to obtain vegetative progeny originated in a BABA-sensitized parental specimen. Progeny of induced plants were generated by in vitro and in vivo propagation, i.e., from lateral buds propagated from in vitro seedlings $\left(\mathrm{B}_{\mathrm{A}}\right)$ and via tubers $\left(\mathrm{B}_{\mathrm{B}}\right)$, respectively. These plants were subsequently cultured to the stage of 7-8 leaves and then inoculated with the oomycete zoospores. A parallel line of non-induced control plants was kept and later exposed to biotic stress to provide a comprehensive comparison of BABA-treated and non-induced plants $\left(\mathrm{C}_{0}, \mathrm{C}_{0} / \mathrm{C}_{1}\right.$, $\mathrm{C}_{\mathrm{A}}$, and $\mathrm{C}_{\mathrm{B}}$ ). Plant material was collected for analysis at $24 \mathrm{hpi}$. Plants exposed to a $1 \mathrm{mM}$ BABA dose were analysed at 1, 3, 6, and 24 hpi. An outline of the experimental design used in the presented paper is given in Figure 1.

\section{Plant Material}

A susceptible potato cultivar $S$. tuberosum L. 'Bintje' from the Potato Genebank (Plant Breeding and Acclimatization Institute IHAR-PIB in Bonin) was initially derived from in vitro tissue culture and kept in sterile soil in a phytochamber $(16 \mathrm{~h} / 8 \mathrm{~h}$ : day/night; $180 \mu \mathrm{mol} \mathrm{m}^{-2} \mathrm{~s}^{-1}$ ) at $18 \pm 1^{\circ} \mathrm{C}$ and $60 \%$ relative humidity.

\section{Pathogen Culture and Inoculation with $P$. infestans}

Phytophthora infestans (Mont.) de Bary, virulent for 'Bintje' (1.3.4.7.10.11., isolate MP946), was obtained by courtesy from the Plant Breeding and Acclimatization Institute, Research Division in Młochów, Poland. Potato plants were inoculated by spraying leaves with $5 \mathrm{ml}$ of the oomycete zoospore suspension at a concentration of $1.0 \times 10^{5}$ per $1 \mathrm{ml}$ of water and they were kept 


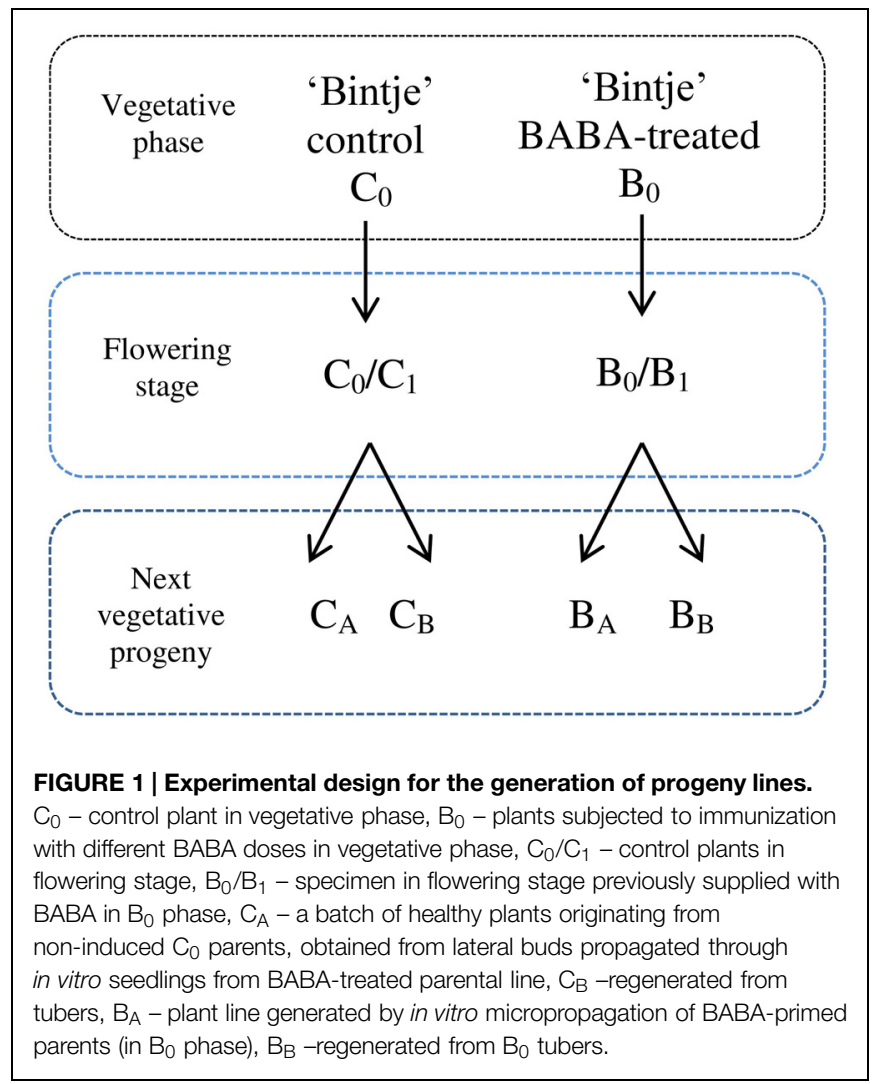

overnight at $100 \%$ relative humidity and $18^{\circ} \mathrm{C}$ and afterward they were transferred to a growth chamber.

\section{Immunization with Different BABA Doses}

The potato susceptible genotype 'Bintje' was immunized by spraying potato leaves with a selected dose of BABA (3 ml per plant; Floryszak-Wieczorek et al., 2012). Concentrations of BABA used in the experiment were as follows: $0.1,1,10$, and $20 \mathrm{mM}$ and they were delivered to plant surface using an atomizer.

\section{Assessment of Disease Index}

The area affected by disease symptoms was assessed on potato leaves 3-7 days after inoculation with $P$. infestans based on a scale from I to IV (James, 1971), which represented the percentage of leaf area covered by late blight symptoms ( $=1-9 \%$; II = 10-24\%; III = 25-49\%; IV = 50-100\%). Disease symptoms were also determined using trypan blue staining of the $P$. infestans mycelium according to the assay proposed by Wilson and Coffey (1980).

\section{Gene Expression Measurement}

The RNA was isolated from $150 \mathrm{mg}$ of frozen leaf tissue using TriReagent $^{\circledR}$ (Sigma) according to the method of Chomczynski and Sacchi (1987). The obtained RNA was purified with the use of a Deoxyribonuclease I Kit (Sigma). For the reverse transcription $1 \mu \mathrm{l}$ of RNA from every experimental variant was processed with a RevertAid ${ }^{\mathrm{TM}}$ Reverse Transcriptase Kit (Thermo Scientific) according to the manufacturer's instructions. Real-time PCR was performed on a Rotor Gene 6000 Thermocycler (Corbett Life Sciences). The reaction mixture contained $0.1 \mu \mathrm{M}$ of each primer, $1 \mu \mathrm{l}$ of $5 \times$ diluted $\mathrm{cDNA}, 10 \mu \mathrm{l}$ of the Power SYBR ${ }^{\circledR}$ Green PCR Master mix (Applied Biosystems) and DEPC-treated water to the total volume of $20 \mu \mathrm{l}$. The real-time PCR reaction conditions included an initial 5-min denaturation at $95^{\circ} \mathrm{C}$, followed by 55 cycles consisting of $10 \mathrm{~s}$ at $95^{\circ} \mathrm{C}, 20 \mathrm{~s}$ at $53^{\circ} \mathrm{C}$ and $30 \mathrm{~s}$ at $72^{\circ} \mathrm{C}$. The reaction was finalized by denaturation at a temperature rising from 72 to $95^{\circ} \mathrm{C}$ at $1^{\circ}$ per $5 \mathrm{~s}$. Reaction specificity was confirmed by the occurrence of one peak in the melting curve analysis.

$P R-1$ primers used in real-time detection were as follows:

F: CCGCGTTGAGCTGGGGGAAA, R: GAGCTGGGGACT GCAGGATGC $\left(T_{\mathrm{m}}=53^{\circ} \mathrm{C}\right)$. The data were normalized to the reference genes encoding the elongation factor (efl $\alpha$, AB061263; F: ATTGGAAACGGATATGCTCCA, R: TCCT TACCTGAACGCCTGTCA, $\left.T_{\mathrm{m}}=53^{\circ} \mathrm{C}\right)$ and $18 \mathrm{~S}$ rRNA (X67238.1, F: GGGCATTCGTATTTCATAGTCAGAG, R: GGT TCTTGATTAATGAAAACATCCT). All used primers were designed using Primer-BLAST (Ye et al., 2012). The $C_{\mathrm{t}}$ values were determined with the use of a Real-time PCR Miner (Zhao and Fernald, 2005) and the relative gene expression was calculated with the use of efficiency corrected calculation models presented by Pfaffl (2004).

\section{Statistical Analysis}

All results were based on at least three independent experiments, each with at least three biological replicates. Analysis of variance was conducted and the least significant differences (LSD) between means were determined using Tukey's test at the significance level $P=0.05$. The SigmaPlot 11.0 software (Systat) was used to perform statistical tests. Randomization was performed during collection of samples in the histochemical assay of trypan blue staining.

\section{RESULTS}

In accordance with the experimental design, presented in Figure 1, the transcript of $P R 1$ gene accumulation was analyzed in systemic leaves of BABA primed potato plants in the short (3 days) and long (28 days) time periods after induction and next, in vegetative progeny of primed plants derived from tubers and from lateral buds through in vitro seedlings. The listed variants of induced plants were subsequently challenge inoculated with $P$. infestans. All the observed changes were referred to the control, i.e., potato plants not subjected to priming or only inoculated with a virulent pathogen. Moreover, the effectiveness of the applied inducer or priming in the acquisition of systemic resistance in potato plants and in the analysis of inheritance of this trait was assessed on the basis of the disease index assay, i.e. the development of potato late blight symptoms.

\section{$P R-1$ Gene Expression in BABA-Primed Parental Potato Plants $\left(B_{0}\right)$}

The effect of various BABA concentrations on PR1 transcript accumulation was analyzed 3 days after the plant treatment $\left(\mathrm{B}_{0}\right.$; Figure $\left.2 \mathrm{~A}\right)$. Generally, the level of $P R 1$ transcripts was not 
A

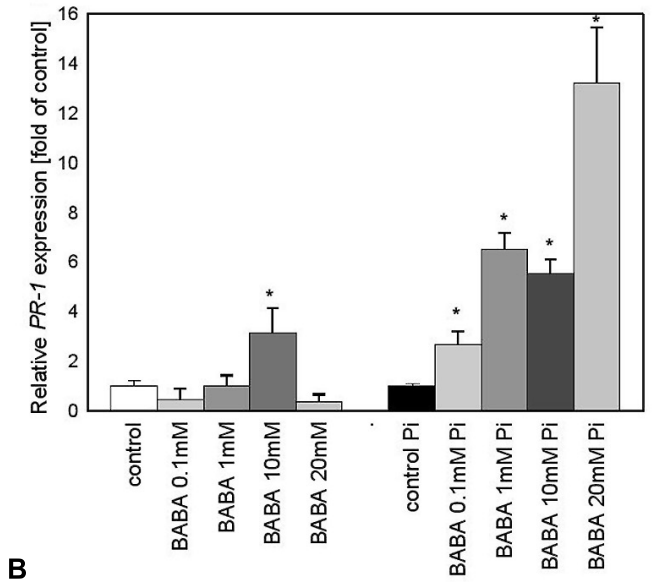

B

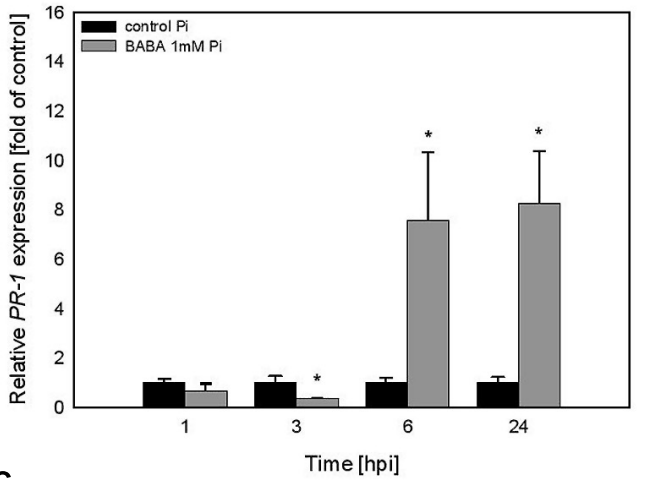

C

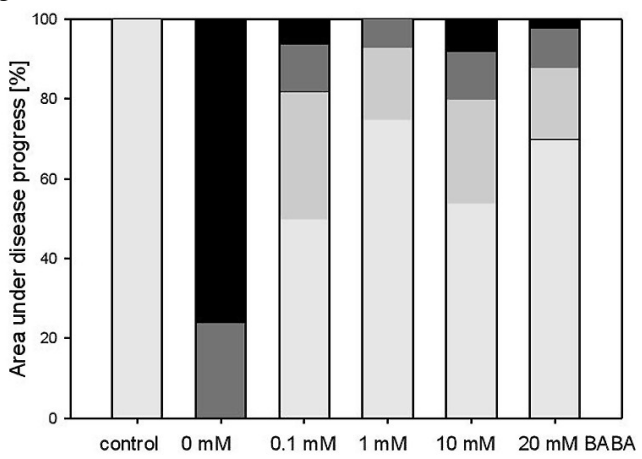

D

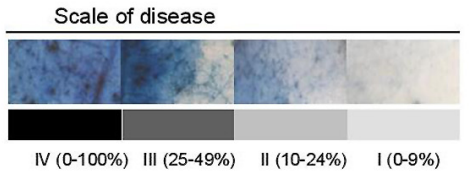

FIGURE 2 | PR-1 gene transcript accumulation and BABA dose-dependent protection against Phytophthora infestans in potato leaves $\left(\mathbf{B}_{\mathbf{0}}\right)$. (A) $P R-1$ gene transcript accumulation at 3 days after induction with BABA (left bars) and $24 \mathrm{~h}$ after inoculation of previously induced plants (right bars), (B) a time-dependent analysis of $P R-1$ gene expression in $P$. infestans-inoculated plants previously treated with $1 \mathrm{mM}$ dose of BABA (in $\mathrm{B}_{0}$ stage), (C) an index of disease development at 7 dpi in directly BABA-treated parents $B_{0}$, (D) a scale corresponding to the area of leaves covered with late blight and to trypan blue staining of $P$. infestans mycelium. *Significantly different from control leaves, $P<0.05$. Values represent means of data $\pm \mathrm{SD}$ of at least three independent experiments, each with at least three biological replicates. elevated in plants exposed to BABA, except for a slight rise in the case of the $10 \mathrm{mM}$ inducer dose. In contrast, BABA-sensitized and then challenge inoculated plants exhibited a high rise in PR1 expression levels from two to sevenfold, depending on the used BABA concentration (Figure 2B). Protection of primed potato plants against $P$. infestans was assessed at 7 days post inoculation (Figure 2C). The index of disease development in potato leaves represents the percentage of leaf area covered by late blight symptoms, classified into four categories according to the degree of leaf tissue colonization by the pathogen (Figure 2D). All applied BABA concentrations exhibited protective effects in terms of disease limitation in comparison to unprimed plants. Because $1 \mathrm{mM}$ BABA-elicited immunity was also effective in plant protection, resulting in approx. $80 \%$ disease spot reduction, we focused on this BABA dose when analyzing PR1 transcript levels at different time points after challenge inoculation. The concern was that the highest concentrations of BABA (10 and $20 \mathrm{mM})$ could induce hyperergic defense effects or be transferred to the next generation.

Thus, we found that the time course of $P R 1 \mathrm{mRNA}$ expression in $1 \mathrm{mM} \mathrm{BABA}$-treated and subsequently inoculated potato leaves showed a 10 -fold higher expression level, peaking at 6 and $24 \mathrm{hpi}$ in relation to unprimed and inoculated plants (Figure 2B).

\section{$P R-1$ Gene Expression in BABA-primed Parental Potato After its Passage to the Generative Stage $\left(B_{0} / B_{1}\right)$}

To confirm that priming is not reversed after establishment of flower buds by potato plants we performed experiments over a longer time period after BABA-treatment of parental plants. A slightly more intensive PR1 expression level (ranging from 1.2 to 2.2), correlated with increased BABA concentrations, was found in potato leaves at 28 days (Figure $\mathbf{3 A}$ ) in comparison to 3 days after the treatment (Figure 2A). In turn, the BABAmediated mRNA transcript for $P R 1$ was rapidly up-regulated after challenge inoculation and - interestingly - it was the most elevated (10-hold higher) in $1 \mathrm{mM} \mathrm{BABA}$ supplied plants (Figure 3A). An independent analysis of PR1 time expression patterns revealed that potato plants pretreated with $1 \mathrm{mM}$ BABA showed an earlier expression (since $1 \mathrm{hpi}$ ) and a higher transcription abundance (up to $24 \mathrm{hpi}$ ) than unprimed plants (Figure 3B). Furthermore, BABA-primed potato plants $\mathrm{B}_{0} / \mathrm{B}_{1}$ showed enhanced resistance against $P$. infestans compared to $\mathrm{C}_{0} / \mathrm{C}_{1}$ (Figure 3C). Plants from this progeny, previously treated with $1 \mathrm{mM} \mathrm{BABA}$, exhibited nearly $70 \%$ reduction of late blight symptoms.

\section{Transcript Accumulation of $P R 1$ in Vegetative Progeny of BABA-primed Plants Derived from Tubers $\left(B_{B}\right)$}

To examine the persistence of stress memory in the case of acquired resistance we analyzed potato progeny grown from tubers generated from primed plants $\left(B_{B}\right.$ line). Obtained data revealed a similar tendency in $P R 1$ gene activation and immunity as it was found in BABA-primed parental plants. Thus vegetative offspring produced from potato tubers showed a slight expression 


\section{A}

B
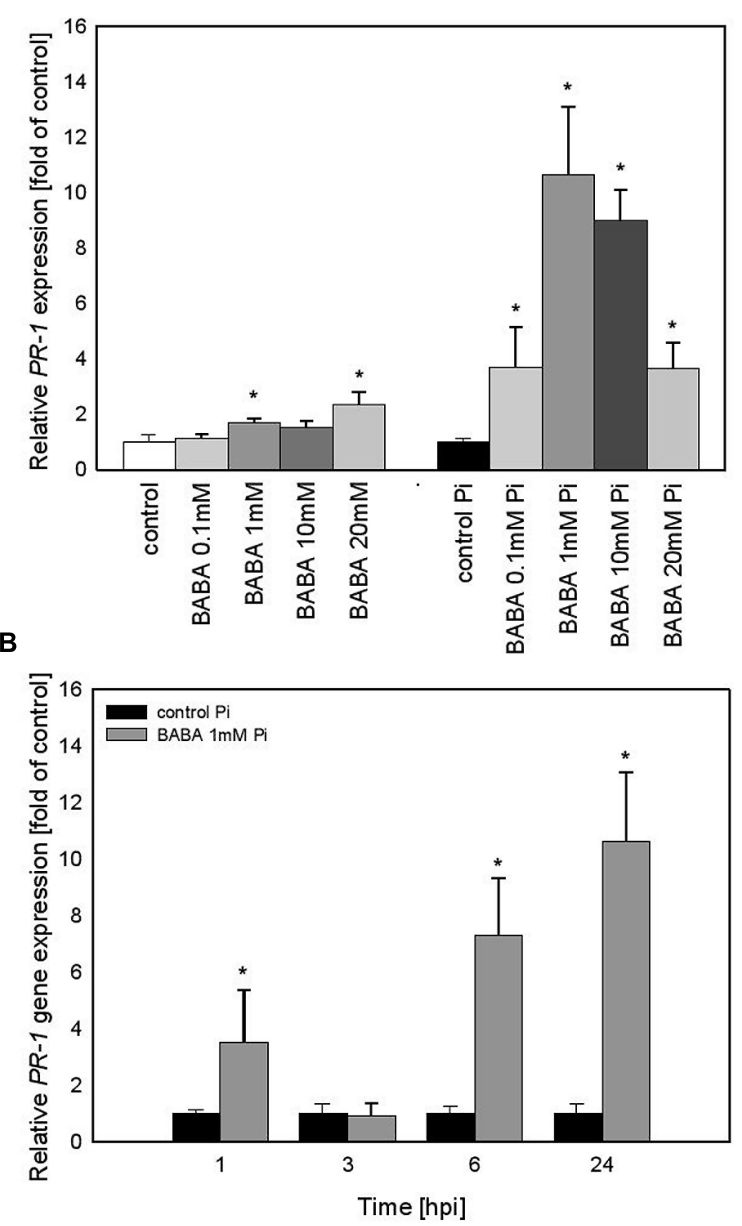

C

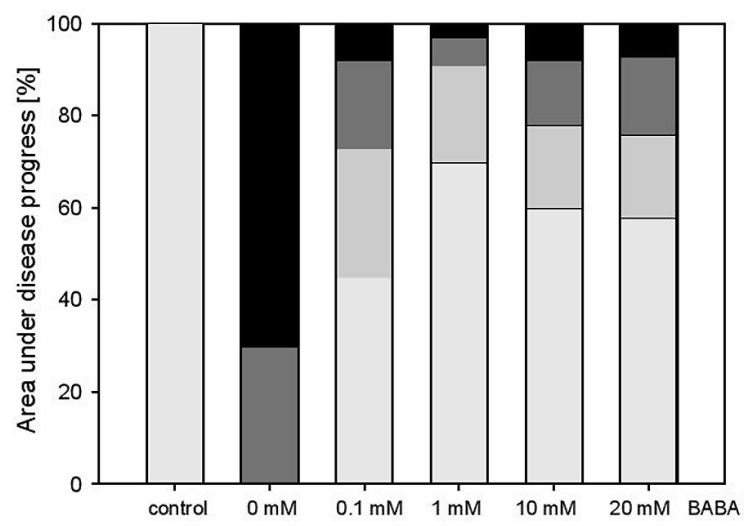

FIGURE 3 | PR-1 gene transcript accumulation and BABA dose-dependent protection against $P$. infestans in the flowering stage $\left(\mathbf{B}_{0} / \mathbf{B}_{1}\right)$ of BABA-treated parent plants. (A) $P R-1$ gene transcript accumulation 28 days after induction with BABA (left bars) and after inoculation of previously immunized plants (at $24 \mathrm{hpi}$; right bars), (B) a time-dependent analysis of $P R-1$ gene expression in $P$. infestans-inoculated plants previously treated with $1 \mathrm{mM}$ dose of BABA ( 28 days earlier). (C) disease development index at $7 \mathrm{dpi}$ in the BABA-treated parents in flowering stage $\left(\mathrm{B}_{0} / \mathrm{B}_{1}\right)$. * Significantly different from control leaves, $P<0.05$. Values represent the means of data $\pm S D$ of at least three independent experiments, each with at least three biological replicates. of PR1 before inoculation and an enhanced PR1 induction upon potent challenge with the oomycete pathogen (Figure 4A). Analysis of progeny of $1 \mathrm{mM}$ BABA primed plants revealed

A

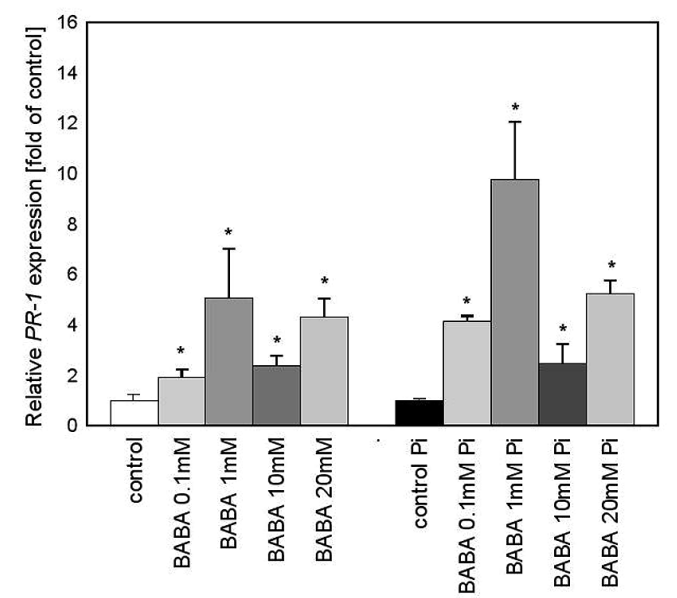

B

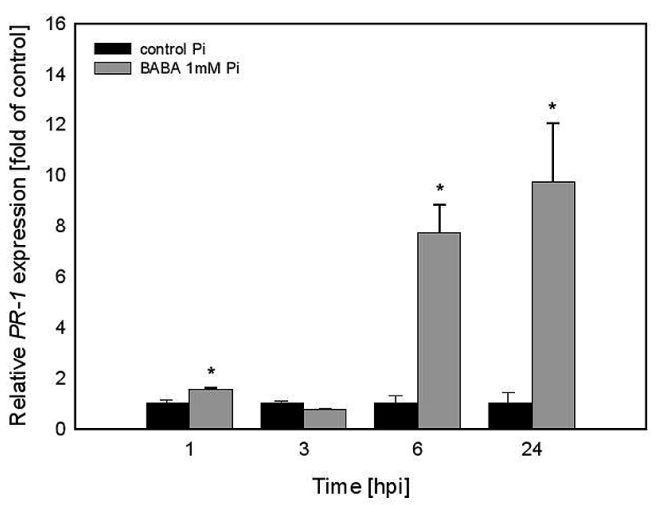

C

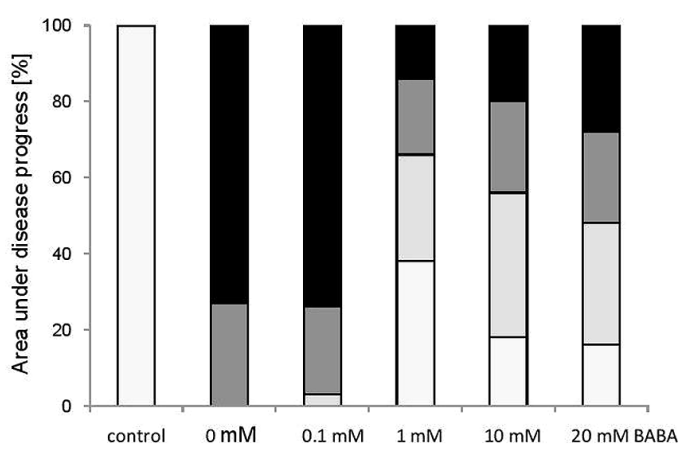

FIGURE 4 | PR-1 gene transcript accumulation in progeny lines of immunized potato plants ( $B_{B}$ stage) -offspring received from the BABA-treated parental line with use of tubers. (A) After induction of $\mathrm{B}_{0}$-originated plants with BABA (left bars) and $24 \mathrm{~h}$ after inoculation of previously immunized plants (right bars), (B) a time-dependent analysis of $P R$-1 gene expression in $P$. infestans-inoculated plants obtained from the tubers of plants exposed to $1 \mathrm{mM} \mathrm{BABA}$ (in $\mathrm{B}_{0}$ stage), (C) disease development index at $7 \mathrm{dpi}$ in the BABA-treated parental line with use of tubers, *significantly different from control leaves, $P<0.05$. Values represent means of data \pm SD of at least three independent experiments, each with at least three biological replicates. 
a long-lasting impact on time-dependent kinetics of $P R 1$ gene expression augmented at 6 and 24 hpi (Figure 4B). Moreover, it was documented that primed progeny of induced plants retained an acquired systemic resistance to $P$. infestans in the form of approx. Sixty percentage diminished disease spot area compared to the infected unprimed leaves (Figure 4C).

\section{Transcript Accumulation of $P R 1$ in Vegetative Progeny of BABA-primed Plants Derived from Lateral Buds Propagated Through in Vitro Seedlings $\left(B_{A}\right)$}

Vegetative progeny of induced potato plants through in vitro culture showed sensitization to $P R 1$ priming triggered by BABA and thus created a stress imprint activation, facilitating acquisition of a competence to react faster after challenge inoculation. It was reflected in the minimal rise of PR1 levels before infection and an enhanced induction of the gene expression upon pathogen treatment (Figure 5A). Vegetative progeny of $1 \mathrm{mM}$ BABA-primed plants derived from lateral buds (Figure 5B) displayed comparable kinetics and slightly less intensity of PR1 transcript accumulation than those of primed progenies grown from tubers in the successive $24 \mathrm{~h}$ after challenge inoculation (Figure 4B).

Summing up, the primed state of the susceptible potato cultivar (cv. Bintje) was transferred to its vegetative progeny as a potentiated $P R 1$ gene expression following challenge inoculation. Nevertheless, the potato plants from in vitro cultures have largely lost the trait of acquired resistance to $P$. infestans and the leaf area affected by late blight was similar to that of the infected control (Figure 5C).

\section{DISCUSSION}

Results on the sequential potato plant treatment with BABA followed by the virulent $P$. infestans challenge inoculation provided data on the imprint of post-stress information and its long persistence until fertilization, in the form of an enhanced PR1 transcript accumulation and a transient improvement of acquired resistance to the late blight disease.

A very important issue in evaluating the effectiveness of SAR is connected with the proper selection of informative markers for the trait acquired by the plant and potentially enhanced or inherited. Generally it is known that establishment of SAR is closely related with systemic activation of pathogenesis-related $(P R)$ genes coding plant defense proteins (Ryals et al., 1996). There is increasing evidence that among various $P R$ genes the $P R 1$ gene is the most responsive to priming in an inducedparental plant and its progeny (Luna and Ton, 2012; Luna et al., 2014b). In priming for defense the key issue is that PR1 gene expression as a good fingerprint of BABA-induced is mainly switched on after challenge inoculation. Our results showed that both potato plants directly exposed to BABA $\left(\mathrm{B}_{0}\right.$ and $\left.\mathrm{B}_{0} / \mathrm{B}_{1}\right)$ and their vegetative progenies $\left(\mathrm{B}_{\mathrm{A}}\right.$ and $\left.\mathrm{B}_{\mathrm{B}}\right)$ were sensitized to priming of $P R 1$, thus they displayed stress memory of the previous
A

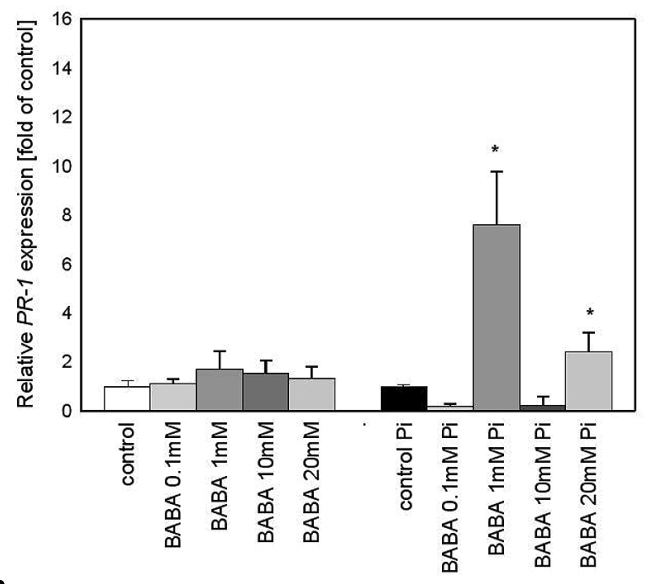

B

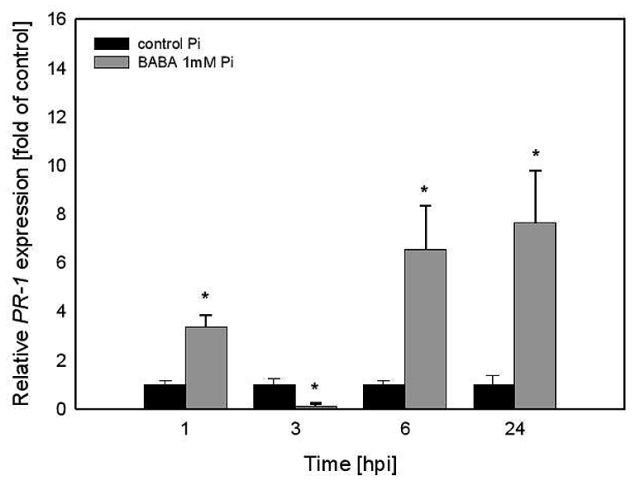

C

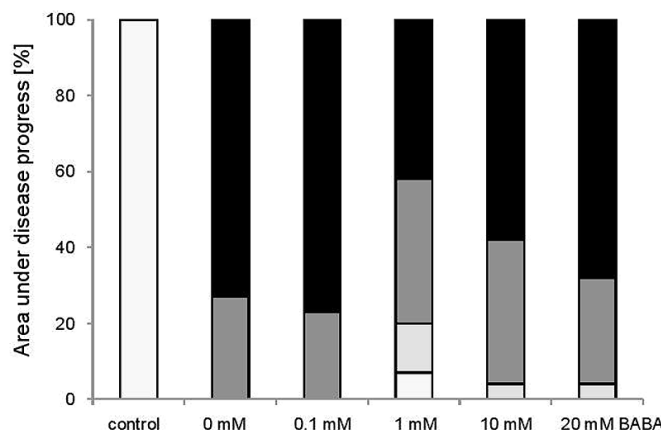

FIGURE $5 \mid P R-1$ gene transcript accumulation in progeny lines of immunized potato plants $\left(B_{A}\right)$ - offspring received from the BABA-treated parental line with use of plants derived from lateral buds propagated from in vitro seedlings. (A) After induction of

$\mathrm{B}_{0}$-originated plants with BABA (left bars) and $24 \mathrm{~h}$ after inoculation of previously immunized plants (right bars), (B) a time-dependent analysis of $P R-1$ gene expression in $P$. infestans-inoculated plants obtained from the parent sensitized with $1 \mathrm{mM} B A B A$ (in $B_{0}$ stage). (C) disease development index at $7 \mathrm{dpi}$ in the BABA-treated parental line with use of plants derived from lateral buds propagated from in vitro seedlings, *significantly different from control leaves, $P<0.05$. Values represent means of data $\pm \mathrm{SD}$ of at least three independent experiments, each with at least three biological replicates.

treatments, to which their parental plants had been subjected to. Importantly, BABA pretreatment induced either minimal or no PR1 gene expression, but the metabolic memory of the treatment 
had to be saved and appeared as the consequence of the pathogen attack. Therefore, transient enhancement of the $P R 1$ transcript level has been revealed only when the plant was challenged with $P$. infestans in the same generation-primed potato and its next vegetative progeny.

When analyzing the long history of research on SAR in plants it needs to be stressed that research hypotheses proposed in relation to this problem, apart from supporters, have also been questioned by many opponents (Heidel et al., 2004; Walters and Heil, 2007). A frequently quoted argument against SAR was connected with the reservation concerning yield reduction and variation in plant responsiveness to defense elicitors caused by genotype and environment (Bruce, 2014). It was also emphasized that acquired resistance is reversed upon entering the reproductive phase by plants, due to the altered phytohormone balance (Molinier et al., 2006; Pecinka and Scheid, 2012; Banday and Nandi, 2015). Therefore BABA priming efficiency was analyzed by us in potato plants in the flowering state. Obtained data revealed that memory of sensitization had to be retained in potato plants, as in the presence of the pathogen the level of PR1 increased (10-hold) at 28 days after the BABA treatment.

Jakab et al. (2001) in Arabidopsis thaliana showed that BABA applied as a foliar spray, in contrast to soil drench, even at low concentrations, enhanced the accumulation of PR1 mRNA. Moreover, both experimental approaches led to the induction of resistance, suggesting that in this case the establishment of resistance could be independent of PR1 expression. Generally speaking, PR1 accumulation is highly dependent on plant genotype and may change significantly under controlled conditions of the phytochamber when compared to the uncontrolled conditions found in the greenhouse or in the field (Cohen et al., 1994; Cohen, 2002). Hence, different mechanisms of protection are effective against distinct pathogens, and BABA can prime the plant to arrange such pathogen-specific responses much faster (Zimmerli et al., 2000).

To study the transmission of the BABA-primed effects to the vegetative potato progenies we observed the persistent state of priming in the form of enhanced $P R 1$ expression and slowed down development of late blight symptoms on leaves of plant obtained from tubers. Thereby we found that the primed state in the sensitized potato $\mathrm{cv}$. Bintje was preserved over one generation and translated to the descendants propagated through mitotic divisions. Because potato cultivars usually far more resistant to $P$. infestans are commercially propagated by tubers, obtained data may be of great practical importance. Late blight in the field can progress very rapidly and destroy potato foliage within a very short time under favorable weather conditions, causing annual losses from a few to several billion dollars worldwide (Schepers et al., 2009; Hu et al., 2012). BABA-primed resistance might provide new tools to improve crop protection thanks to the enhanced natural defense ability of potato plants to $P$. infestans or the reduced use of fungicide (Liljeroth et al., 2010).

The effectiveness of BABA to induce resistance against P. infestans was explored by Olivieri et al. (2009) in potato cultivars differing in their level of resistance to late blight. Obtained tubers from BABA treated plants, challenge inoculated with $P$. infestans, showed a much more pronounced increase in phenol and phytoalexin levels in resistant (cv. Pampeana) rather than in susceptible (cv. Bintje) potato plants, when compared to untreated ones. Likewise, in both the abovementioned potato cultivars BABA pretreatment improved the yield of harvested tubers. Cultivar-dependent differences in the response to BABA application were also studied by Bengtsson et al. (2014). The results confirmed previous data (Olivieri et al., 2009) that BABA treatment enhanced resistance of potatoes, although the efficiency of BABA supply differs between potato cultivars. Thus, in a more resistant cv. Ontario both a significant reduction in $P$. infestans growth and the activation of various defense responses were faster and stronger than in cv. Bintje (Bengtsson et al., 2014). However, according to these authors the observed changes should be rather attributed to direct defense responses of potato, rather than primed ones.

Our results demonstrate that the primed state for defense of a susceptible potato cultivar (cv. Bintje) is transmitted to its vegetative progeny as a potentiated $P R 1 \mathrm{mRNA}$ accumulation after further challenge with $P$. infestans, with protection against pathogen attack in plants derived from tubers. Despite the similarities in the PR1 transcriptional response, plants derived from lateral buds propagated through in vitro seedlings revealed a lesser potential to switch on effective defense pathways to the oomycete pathogen. Generally each BABA-primed genotype, including $\mathrm{cv}$. Bintje, possesses the capacity to mobilize post-stress responses via SA-dependent and/or JA/ethylenedependent regulatory pathways within its own defense threshold to face the following challenge infection. A relatively low basal resistance of the susceptible $\mathrm{cv}$. Bintje was not sufficient to effectively defend plants of the next primed progeny from in vitro against the oomycete pathogen. Apart from the PR1 gene expression analyzed in our experiment, priming leads to an augmented activation of multi-genic defense mechanisms (Ahmad et al., 2010). It has not been excluded that plant exposure under in vitro conditions could affect potato seedling responsiveness.

According to Bruce (2014), induced plant defense is a complex phenomenon and its high variability depends on plant genetics and physiology, while it may also be altered by environmental conditions. Moreover, experiments conducted on 32 tomato accessions using BABA revealed that protection of induced plants against $P$. infestans was not identical on accessions exhibiting the same level of susceptibility and both leaf position and isolate interacted with inducibility (Sharma et al., 2009). In the next experimental approach they confirmed the previous statement that the level of induced defense was not always related to the resistance level of the tomato accession and it was significantly influenced by the pathogen isolate used for challenge inoculation (Sharma et al., 2010). Thus, insight into the molecular basis of priming for defense becomes therefore absolutely essential and will significantly facilitate increased plant basal resistance without negative or compromise effects. 
Another significant problem in BABA application as a crop defense activator is connected with the inhibition of plant growth when used in high doses (van Hulten et al., 2006; Walters and Heil, 2007). Recent studies of Luna et al. (2014a) revealed that cellular perception of BABA is mediated by aspartyltRNAsynthetase (AspRS) encoded by the IMPAIRED IN BABAINDUCED IMMUNITY 1 (INB1) gene. They documented the functioning of two separate regulatory pathways managed by $I B I 1$, using the A. thaliana mutant impaired in BABA-induced disease immunity (ibi1), but which was hypersensitive to BABAinduced growth repression. According to the authors, an in-depth clarification of these independent molecular mechanisms opens new possibilities to engineer constitutively primed plants without BABA treatment and growth inhibition (Schwarzenbacher et al., 2014).

The concept of epigenetic control of defense priming has been generally accepted by many research groups; however,

\section{REFERENCES}

Ahmad, S., Gordon-Weeks, R., Pickett, J., and Ton, J. (2010). Natural variation in priming of basal resistance: from evolutionary origin to agricultural exploitation. Mol. Plant Pathol. 11, 817-827. doi: 10.1111/j.13643703.2010.00645.x

Andreu, A. B., Guevara, M. G., Wolski, E. A., Daleo, G. R., and Caldiz, D. O. (2006). Enhancement of natural disease resistance in potatoes by chemicals. Pest Manag. Sci. 62, 162-170. doi: 10.1002/ps.1142

Baider, A., and Cohen, Y. (2003). Synergistic interaction between BABA and mancozeb in controlling Phytophthora infestans in potato and tomato and Pseudoperonospora cubensis in cucumber. Phytoparasitica 31, 399-409. doi: 10.1007/BF02979812

Banday, Z. Z., and Nandi, A. K. (2015). Interconnection between flowering time control and activation of systemic acquired resistance. Front. Plant Sci. 6:174. doi: $10.3389 /$ fpls.2015.00174

Bektas, Y., and Eulgem, T. (2015). Synthetic plant defense elicitors. Front. Plant Sci. 5:804. doi: 10.3389/fpls.2014.00804

Bengtsson, T., Holefors, A., Witzell, J., Andreasson, E., and Liljeroth, E. (2014). Activation of defense responses to Phytophthora infestans in potato by BABA. Plant Pathol. 63, 193-202. doi: 10.1111/ppa.12069

Bruce, T. J. A. (2014). Variation in plant responsiveness to defense elicitors caused by genotype and environment. Front. Plant Sci. 5:349. doi: 10.3389/fpls.2014.00349

Bruce, T. J. A., Matthes, M. C., Napier, J. A., and Pickett, J. A. (2007). Stressful "memories" of plants: evidence and possible mechanisms. Plant Sci. 173, 603608. doi: 10.1016/j.plantsci.2007.09.002

Chomczynski, P., and Sacchi, N. (1987). Single-step method of RNA isolation by acid quanidiniumthiocyanate-phenol-chloroform extraction. Anal. Biochem. 162, 156-159. doi: 10.1006/abio.1987.9999

Cohen, Y. R. (2002). $\beta$-aminobutyric acid-induced resistance against plant pathogens. Plant Dis. 86, 448-457. doi: 10.1094/PDIS.2002.86.5.448

Cohen, Y. R., Niderman, T., Mosinger, E., and Fluhr, R. (1994). $\beta$-Aminobutyric acid Induces the accumulation of pathogenesis-related proteins in tomato (Lycopersicon Esculentum L.) plants and resistance to late blight infection caused by Phytophthora infestans. Plant Physiol. 104, 59-66.

Conrath, U. (2011). Molecular aspects of defense priming. Trends Plant Sci. 16, 524-531. doi: 10.1016/j.tplants.2011.06.004

Dubreuil-Maurizi, C., Trouvelot, S., Frettinger, P., Pugin, A., Wendehenne, D., and Poinssot, B. (2010). $\beta$-Aminobutyric acid primes an NADPH oxidasedependent reactive oxygen species production during grapevine-triggered immunity. Mol. Plant Microbe Interact. 23, 1012-1021. doi: 10.1094/MPMI-238-1012

Floryszak-Wieczorek, J., Arasimowicz-Jelonek, M., Milczarek, G., Janus, L., Pawlak-Sprada, S., Abramowski, D., et al. (2012). Nitric oxide-mediated stress imprint in potato as an effect of exposure to a priming agent. more details on this phenomenon will be needed (van den Burg and Takken, 2009; Luna and Ton, 2012; Luna et al., 2014b). We assumed in our experimental approach that obtaining successive vegetative generations of a highly susceptible potato cultivar with the state of increased alertness in the form of enhanced PR1 expression toward virulent $P$. infestans provides the starting point for the identification of molecular carriers of such inherited post-stress information. It will also be interesting to learn where lies a functional link between the state of readiness and the executive state of plant immunity.

\section{ACKNOWLEDGMENT}

This study was funded from the National Science Centre (2013/11/B/NZ9/01903).

Mol. Plant. Microbe Interact. 25, 1469-1477. doi: 10.1094/MPMI-02-120044-R

Fu, Z. Q., and Dong, X. (2013). Systemic acquired resistance: turning local infection into global defense. Ann. Rev. Plant Biol. 64, 839-863. doi: 10.1146/annurevarplant-042811-105606

Hamiduzzaman, M. M., Jakab, G., Barnavon, L., Neuhaus, J.-M., and MauchMani, B. (2005). $\beta$-Aminobutyric acid-induced resistance against downy mildew in grapevine acts through the potentiation of callose formation and jasmonic acid signaling. Mol. Plant Microbe Interact. 18, 819-829. doi: 10.1094/MPMI-18-0819

Haverkort, A. J., Struik, P. C., Visser, R. G. F., and Jacobsen, E. (2009). Applied biotechnology to combat late blight in potato caused by Phytophthora infestans. Potato Res. 52, 249-264. doi: 10.1007/s11540-009-9136-3

Heidel, A. J., Clarke, J., Antonovics, J., and Dong, X. (2004). Fitness costs of mutations affecting the systemic acquired resistance pathway in Arabidopsis thaliana. Genetics 168, 2197-2206. doi: 10.1534/genetics.104.032193

Hu, C.-H., Perez, F. G., Donahoo, R., McLeod, A., Myers, K., Ivors, K., et al. (2012). Recent genotypes of Phytophthora infestans in the eastern united states reveal clonal populations and reappearance of mefenoxam sensitivity. Plant Dis. 96, 1323-1330. doi: 10.1094/PDIS-03-11-0156-RE

Jakab, G., Cottier, V., Toquin, V., Rigoli, G., Zimmerli, L., Metraux, J. P., et al. (2001). $\beta$-aminobutyric acid-induced resistance in plants. Eur. J. Plant Pathol. 107, 29-37. doi: 10.1023/A:1008730721037

James, W. C. (1971). An illustrated series of assessment keys for plant diseases, their preparation and usage. Can. Plant Dis. Surv. 51, 39-65.

Janus, Ł, Milczarek, G., Arasimowicz-Jelonek, M., Abramowski, D., Billert, H., and Floryszak-Wieczorek, J. (2013). Normoergic NO-dependent changes, triggered by a SAR inducer in potato, create more potent defense responses to Phytophthora infestans. Plant Sci. 211, 23-34. doi: 10.1016/j.plantsci.2013.06.007

Liljeroth, E., Bengtsson, T., Wiik, L., and Andreasson, E. (2010). Induced resistance in potato to Phytphthora infestans-effects of BABA in greenhouse and field tests with different potato varieties. Eur. J. Plant Pathol. 127, 171-183. doi: 10.1007/s10658-010-9599-8

Luna, E., Bruce, T. J. A., Roberts, M. R., Flors, V., and Ton, J. (2012). Nextgeneration systemic acquired resistance. Plant Physiol. 158, 844-853. doi: 10.1104/pp.111.187468

Luna, E., and Ton, J. (2012). The epigenetic machinery controlling transgenerational systemic acquired resistance. Plant Signal. Behav. 7, 615-618. doi: 10.4161/psb.20155

Luna, E., van Hulten, M., Zhang, Y., Berkowitz, O., López, A., Pétriacq, P., et al. (2014a). Plant perception of $\beta$-aminobutyric acid is mediated by an aspartyltRNAsynthetase. Nat. Chem. Biol. 10, 450-456. doi: 10.1038/nchembio.1520

Luna, E., López, A., Kooiman, J., and Ton, J. (2014b). Role of NPR1 and KYP in long-lasting induced resistance by $\beta$-aminobutyric acid. Front. Plant Sci. 5:184. doi: $10.3389 /$ fpls.2014.00184 
Molinier, J., Ries, G., Zipfel, C., and Hohn, B. (2006). Transgeneration memory of stress in plants. Nature 442, 1046-1049. doi: 10.1038/nature05022

Olivieri, F. P., Lobato, M. C., González Altamiranda, E., Daleo, G. R., Huarte, M., Guevara, M. G., et al. (2009). BABA effects on the behaviour of potato cultivars infected by Phytophthora infestans and Fusarium solani. Eur. J. Plant Pathol. 123, 47-56. doi: 10.1007/s10658-008-9340-z

Oostendorp, M., Kuntz, W., Dietrich, B., and Staub, T. (2001). Induced disease resistance in plants by chemicals. Eur. J. Plant Pathol. 107, 19-28. doi: 10.1023/A:1008760518772

Pastor, V., Luna, E., Mauch-Mani, B., Ton, J., and Flors, V. (2013). Primed plants do not forget. Environ. Exp. Bot. 94, 46-56. doi: 10.1016/j.envexpbot.2012.02.013

Pecinka, A., and Scheid, M. O. (2012). Stress-induced chromatin changes: a critical view on their heritability. Plant Cell Physiol. 53, 801-808. doi: $10.1093 / \mathrm{pcp} / \mathrm{pcs} 044$

Pfaffl, M. W. (2004). A new mathematical model for relative quantification in real-time RT-PCR. Nucleic Acids Res. 29, 2004-2007.

Pieterse, C. M. J. (2012). Prime time for transgenerational defense. Plant Physiol. $158,545-545$.

Prime-A-Plant Group: Conrath, U., Beckers, G. J. M., Flors, V., García-Agustín, P., Jakab, G., et al. (2006). Priming: getting ready for battle. Mol. Plant Microbe Interact. 19, 1062-1071. doi: 10.1094/MPMI-19-1062

Rasmann, S., De Vos, M., Casteel, C. L., Tian, D., Halitschke, R., Sun, J. Y., et al. (2012). Herbivory in the previous generation primes plants for enhanced insect resistance. Plant Physiol. 158, 854-863. doi: 10.1104/pp.111.187831

Ryals, J. A., Neuenschwande, U. H., Willits, M. G., Molina, A., Steiner, H.-Y., and Hunt, M. D. (1996). Systemic acquired resistance. Plant Cell 8, 1809-1819. doi: $10.1105 /$ tpc.8.10.1809

Schepers, H., Andrivon, D., Gaucher, D., Kapsa, J., Lebecka, R., Nielsen, B., et al. (2009). "Results of the potato case study in the EU-network of excellence, ENDURE," in Special Report No.13. Proceeding of the 11thEuroBlight Workshop, ed. H. T. A. M. Schepers (Norway: PPO Publisher), 320.

Schwarzenbacher, R. E., Luna, E., and Ton, J. (2014). The discovery of the BABA receptor: scientific implications and application potential. Front. Plant Sci. 5:304. doi: 10.3389/fpls.2014.00304

Sharma, K., Butz, A. F., and Finckh, M. R. (2009). "Genetische Variation in der Resistenzinduktion gegenüber Phytophthora infestans bei Tomaten," in Beiträgezur 10. Wissenschaftstagung ÖkologischerLandbau. Ökologischer Landbau der Zukunft, Zürich, Schweiz, eds J. Mayer, T. Alföldi, F. Leiber, D. Dubois, P. Fried, F. Heckendorn, et al. (Berlin: Dr Köster Verlag), 11-13.

Sharma, K., Butz, A. F., and Finckh, M. R. (2010). Effects of host and pathogen genotypes on inducibility of resistance in tomato (Solanum lycopersicum) to Phytophthora infestans: induced late blight resistance in tomato. Plant Pathol. 59, 1062-1071. doi: 10.1111/j.1365-3059.2010.02341.x

Si-Ammour, A., Mauch-Mani, B., and Mauch, F. (2003). Quantification of induced resistance against Phytophthora species expressing GFP as a vital marker: $\beta$-aminobutyric acid but not BTH protects potato and Arabidopsis from infection. Mol. Plant Pathol. 4, 237-248. doi: 10.1046/j.1364-3703.2003.00168.x
Slaughter, A., Daniel, X., Flors, V., Luna, E., Hohn, B., and Mauch-Mani, B. (2012). Descendants of primed Arabidopsis plants exhibit resistance to botic stress. Plant Physiol. 158, 835-843. doi: 10.1104/pp.111.191593

Ton, J., Jakab, G., Toquin, V., Flors, V., Iavicoli, A., Maeder, M. N., et al. (2005). Dissecting the $\beta$-aminobutyric acid-induced priming phenomenon in Arabidopsis. Plant Cell 17, 987-999. doi: 10.1105/tpc.104.029728

Ton, J., and Mauch-Mani, B. (2004). $\beta$-amino-butyric acid-induced resistance against necrotrophic pathogens is based on ABA-dependent priming for callose. Plant J. Cell Mol. Biol. 38, 119-130. doi: 10.1111/j.1365-313X.2004. 02028.x

van den Burg, H. A., and Takken, F. L. W. (2009). Does chromatin remodeling mark systemic acquired resistance? Trends Plant Sci. 14, 286-294. doi: 10.1016/j.tplants.2009.02.003

van Hulten, M., Pelser, M., van Loon, L. C., Pieterse, M. J., and Ton, J. (2006). Costs and benefits of priming for defense in Arabidopsis. Proc. Natl. Acad. Sci. U.S.A. 103, 5602-5607. doi: 10.1073/pnas.0510213103

Walters, D., and Heil, M. (2007). Costs and trade-offs associated with induced resistance. Physiol. Mol. Plant Pathol. 71, 3-17. doi: 10.1016/j.pmpp.2007.09.008

Wilson, U. E., and Coffey, M. D. (1980). Cytological evaluation of general resistance to Phytophthora infestans in potato foliage. Ann. Bot. 45, 81-90.

Worrall, D., Holroyd, G. H., Moore, J. P., Glowacz, M., Croft, P., Taylor, J. E., et al. (2012). Treating seeds with activators of plant defense generates long-lasting priming of resistance to pests and pathogens. New Phytol 193, 770-778. doi: $10.1111 / \mathrm{j} .1469-8137.2011 .03987 . \mathrm{x}$

Ye, J., Coulouris, G., Zaretskaya, I., Cutcutache, I., Rozen, S., and Madden, T. L. (2012). Primer-BLAST: a tool to design target-specific primers for polymerase chain reaction. BMC Bioinformatics 13:134. doi: 10.1186/1471-2105-13-134

Zhang, X. (2008). The epigenetic landscape of plants. Science 320, 489-492. doi: $10.1126 /$ science. 1153996

Zhao, S., and Fernald, R. D. (2005). Comprehensive algorithm for quantitative real-time polymerase chain reaction. J. Comput. Biol. 12, 1047-1064. doi: $10.1089 / \mathrm{cmb} .2005 .12 .1047$

Zimmerli, L., Jakab, G., Metraux, J. P., and Mauch-Mani, B. (2000). Potentiation of pathogen-specific defense mechanisms in Arabidopsis by $\beta$-aminobutyric acid. Proc. Natl. Acad. Sci. U.S.A. 97, 12920-12925. doi: 10.1073/pnas.230416897

Conflict of Interest Statement: The authors declare that the research was conducted in the absence of any commercial or financial relationships that could be construed as a potential conflict of interest.

Copyright (@) 2015 Floryszak-Wieczorek, Arasimowicz-Jelonek and Abramowski. This is an open-access article distributed under the terms of the Creative Commons Attribution License (CC BY). The use, distribution or reproduction in other forums is permitted, provided the original author(s) or licensor are credited and that the original publication in this journal is cited, in accordance with accepted academic practice. No use, distribution or reproduction is permitted which does not comply with these terms. 